\title{
Groups' contribution to shaping ethnic residential segregation: a dynamic approach
}

\author{
Eduardo Tapia ${ }^{1}$ (D)
}

Received: 1 September 2020 / Accepted: 17 August 2021 / Published online: 27 August 2021

(c) The Author(s) 2021

\begin{abstract}
Some have argued it is possible to infer different groups' contributions to ethnic residential segregation from their individual neighborhood preferences. From this perspective, natives tend to be more segregation-promoting than non-natives, since they prefer neighborhoods where they are the majority. It remains unclear, however, whether this holds when one evaluates their contributions to segregation within a dynamic perspective. Using register data from Statistics Sweden, I define and model ten different groups' residential behavior based on their ethnicity and family composition. I thereby simulate the residential mobility of the full population of Stockholm municipality residents from 1998 to 2012 . Even though my results at the micro-level are consistent with previous studies, the simulation results show that foreign singles' mobility patterns are more segregation-promoting than any other groups, since this group shows a greater in-group feedback effect regarding choice of new neighborhoods, an effect that increases their flow from low-to-high segregated neighborhoods progressively. My results suggest that (1) integration initiatives would be more efficient if focused on this particular group and (2) a proper evaluation of micro-behaviors' implications for macro-patterns of segregation requires a dynamic approach accounting for groups' heterogeneous behaviors and their main interdependencies on shaping segregation over time.
\end{abstract}

Keywords Ethnic residential segregation · Residential segregation dynamics · Large-scale empirically-calibrated simulation models · Analytical sociology

Eduardo Tapia

eduardo.tapia@liu.se

1 The Institute for Analytical Sociology, Linköping University, Kopparhammaren 2, Campus

Norrköping, Linköping, Sweden 


\section{Introduction}

Ethnic residential segregation (henceforth "ERS") is a predominant issue in modern societies. Its adverse consequences for achieving societies inclusive in earnings, health, or education are among the top priorities of academic and political agendas $[3,19,23,39,53,58,61]$. Previous investigations state that the selective inter-neighborhood mobility of households who base their residential choices on distinct ethnic and socioeconomic neighborhood preferences cause ERS. From this perspective, households leave and avoid neighborhoods that do not satisfy their preferences and eventually stratify themselves unevenly across cities. This approach has led to two key assertions in the literature. First, household neighborhood ethnic preferences inform the level of segregation at the macro-level and, second, groups' contributions to shaping segregation derive directly from those preferences. This study aims to challenge these statements. Building on dependence theories of individual choice, which state that individual actions are contingent on others' actions and that this reliance produces emergent results at the macro-level not straightforwardly derivable from individual choices [27, 54], I evaluate groups' relative contributions to ERS.

To study how much different groups contribute to shaping ERS patterns while taking into account their dependencies and their cumulative effects on segregation patterns, I implement a large-scale empirically calibrated simulation model of ERS in which the behavioral (neighborhood choice) and structural components of the model (e.g., income distribution, households' spatial location, group shares, etc.) reflect unique micro-data from Swedish population registers from 1998 to 2012. Based on previous studies showing that households' neighborhood choices depend strongly on their ethnic backgrounds (native, non-native, or mixed) and, more recently, on their family compositions (single, single-children, couple, or couple-children), I define and model ten household groups' residential choices by applying conditional logit models to simulate their residential mobility over the years.

Using the simulation model, I assess counterfactual levels of ERS given that a particular group does not consider ethnic and socioeconomic aspects of the neighborhoods in their residential choices [40]. I focus on these specific variables' effects due to their relevance in previous studies analyzing ethnic residential segregation. Contrary to those studies' suggestion, I find the mobility pattern of foreign singles to be the primary contributor to increasing ERS, which I show to be due to this group presenting a substantial in-group feedback effect regarding the choice of new neighborhoods, progressively increasing their flow from low-to-high segregated neighborhoods and, subsequently, setting in motion the opposite flow for Swedish households.

The Stockholm municipality constitutes this study's data pool, an appealing case-study for analyzing ERS due to its peculiar demographic characteristics. The Stockholm municipality is one of the Europe's most immigrant-dense areas, with the highest share of immigrant residents among Nordic cities. About 27\% Stockholm's residents have a non-Swedish background. The city has also hosted a large number of refugees in recent decades. Together, these facts have raised questions in the 
political arena as to how to design integrative actions [47] to settle newcomers in the city while avoiding ERS's detrimental effects [58].

In that sense, identifying groups' contributions to ERS both sheds new light on the general theoretical discussion regarding segregation and, in particular, segregation dynamics, while also, more broadly, facilitating new perspectives on initiatives toward improving inclusion [46], given that this identification is crucial to any political endeavor seeking to palliate ERS's effects [2, 3, 31]. In this respect, my methodological strategy, highly grounded in empirical data and embedded within a holistic framework, provides a reliable scientific tool for evaluating policies and their implications realistically [16].

Below, I present how previous studies have addressed this research question while also elaborating upon my approach. Next, I introduce my methodological strategy in detail. I then present the main findings at three distinct levels: micro-behavior, macro-patterns, and processes analysis. Finally, I summarize my approach, discuss the results, and remark upon some implications for policy initiatives and future ERS studies.

\section{ERS and groups' contributions}

Neighborhood mobility, how households move between neighborhoods, determines ERS, either positively or negatively. This concept has two relevant properties for understanding ERS, and consequently groups' contributions to it: it is both groupdependent and dynamic. The first property states that different groups, based on their ethnic origins, socioeconomic status, or household compositions, move differently between neighborhoods. The second, asserts that this group-specific behavior is interdependent; that is, actions depend on others' actions, and this dependency constantly reshapes neighborhood-decision contexts for future households.

A prominent part of the ERS literature, grounded in a solid empirical foundation, has focused on exploring the group-specific property of neighborhood mobility. The most-studied aspect of this line of research has been households' ethnic background. From this perspective, native households tend to move into native-dominated neighborhoods and to avoid immigrant-dense neighborhoods, whereas non-native households tend to move into more mixed neighborhoods [8, 11, 13, 36, 56, 57].

More recent work on the group-specific property of neighborhood mobility evaluates how household composition mediates the effect of households' ethnicity on neighborhood mobility. For example, [26] finds that native households with young children are more likely than childless ones to leave integrated neighborhoods. Similarly, [42] discovers black singles are more segregated than white couples with children. More recently, using Belgian census data, [14] found that single households tend to live more in mixed neighborhoods. Apart from life-course events associated with these patterns $[15,52]$, some have also argued that socioeconomic differences among distinct household structures and some ethnically driven factors may also play a role [42]. All in all, these diverse tendencies produce unequal distributions of groups across these categories at the macro-level $[42,48]$. 
These micro-level mobility propensities, some have argued, have two main implications at the macro-level. First, non-natives' mobility patterns promote integration in that they tend to move into more integrated neighborhoods. Conversely, natives' strong orientations toward native-dominated neighborhoods are more segregationpromoting. Second, natives' mobility propensities generally lead to their leaving and avoiding immigrant-dense neighborhoods over time, increasing levels of ERS. The terms employed in the literature for these effects are "white flight" and "white avoidance", respectively [7, 18]. Both implications have thus led to the inference that native-mobility behavior is a major contributor to increasing ERS [18, 24, 45, 50]. However, those implications overlook the dynamic property of neighborhood mobility as producing macro-patterns of segregation, demanding in turn an explicit account of the interdependencies underlying the process connecting individual behaviors to the collective outcomes attributed to them.

\section{The micro-macro-link on ERS dynamics}

Identifying how different groups, distinguished by ethnic background and family composition, contribute to shaping ERS thus requires isolating the effect of their residential mobility in promoting or diminishing segregation patterns. The nature of the puzzle necessitates some worthwhile elaboration. First, how different groups affect segregation is an empirical question, not about how segregation emerges within some highly unrealistic fully racially integrated environment, but how the movement of households, given empirically grounded initial conditions, alters segregation over time [40]. It is possible the processes that brought about segregation from massively integrated societies differed from those operating in modern cities. Second, it relates not only to individual factors affecting household mobility but also, and most importantly, to how their movements themselves eventually reshape segregation at the macro-level [30], conditioned on how other households have moved and how they affect one another over time: the dynamic approach $[1,55,60]$.

The last proposition demands studying the interdependency of households' movements as a fundamental link between individual actions and the aggregated results they produce. In this view, the inferences and reductionisms concerning groups' contributions to ERS given their individual residential choices (discussed in the previous section), although appealing and commonsensical [60], lack a suitable analytical strategy for evaluating those choices' effects on aggregated segregation outcomes.

Nevertheless, several investigations in segregation studies have tackled its dynamic aspect. Schelling's model of segregation dynamics [54] is the seminal basis for a significant portion of this literature. Essentially, these models have focused on demonstrating the generative sufficiency of individual behavioral specifications $[6,17,20,64]$ under highly simplified conditions, that is, on whether the models are able to generate macro-segregation patterns. ${ }^{1}$ Highly stylized simulation models are powerful tools for analyzing micro-behaviors' implications within abstract

\footnotetext{
${ }^{1}$ A review of these models appears in Huang et al. [32].
} 
environments theoretically [8], but the simplicity which is a virtue in that endeavor becomes a major limitation when the goal is addressing empirical questions (groups' contribution to it) or deriving policy implications [62].

Another brand of research on segregation dynamics has focused on evaluating the implications of some micro-model assumptions on macro-patterns of segregation. For example, Bruch and Mare [9] find that different forms of functions governing the behavior of agents can produce different patterns of segregation. Similarly, Xie and Zhou [63] show that in-group heterogeneity of ethnic neighborhood preferences yields a lower level of segregation than homogeneity.

Models are instruments for learning from and intervening in the world [44]. This study conceives them as suitable virtual laboratories [37] for investigating the effect of theoretically driven interventions [21, 22, 37] within highly validated model parameters. This modeling approach recovers the idea of neighborhood mobility as a stem concept for analyzing ERS dynamics, accounting empirically for both its behavioral-structural properties and its dynamic aspects. Further, it allows us to address substantive issues otherwise unfeasible to analyze.

Summarizing the argument, different selective mobility patterns at the individual level between groups, based on ethnicity and composition, are necessary but insufficient for understanding groups' contributions to ERS given its dynamic aspect. To examine these dynamics, I will implement a large-scale empirically calibrated simulation model using register data for the entire population of the city of Stockholm.

\section{Data and methods}

My analytical strategy involves three phases. First, I estimate the simulation's behavioral aspects - households' residential mobility-using discrete choice models [5, 43, 59]. More specifically, I apply the adaptation of conditional logit models developed by Bruch and Mare [9, 10] to model neighborhood choices. During the second phase, I implement a large-scale empirically calibrated simulation model wherein agents' neighborhood choices follow the coefficients estimated in the previous phase. Finally, I evaluate a set of counterfactual scenarios where I quantify each groups' contribution while also explaining why distinct groups contribute differently to changing ERS patterns.

Empirically calibrated simulation models [4, 25] allow researchers to represent phenomena realistically, focusing their analyses on a set of empirically theoretically relevant parameters. A practice that has been conceived as a measure of models' quality and reliability [28]. Awareness of this advantage has recently motivated increased use of data in parameterizing simulation models in social sciences regarding a variety of aspects, such as share of ethnic groups [6], neighborhoods' geographical boundaries [17, 64], or agents' spatial distribution [41]. Empirically calibrating simulation parameters to reduce their degrees of freedom, furthermore, helps to improve models' comprehensibility. Although highly empirically calibrated models can augment model complexity by enabling a greater number of parameters, paradoxically, keeping them realistically fixed allows researchers to focus more 
attention and effort on (1) studying down-to-earth research questions by counterfactually evaluating the effects of one dimension of the model, and, most importantly, (2) analyzing the processes triggered [4, 38] following interventions in the model, that is, prise open the black box of the model results.

The simulation model implemented in this study simulates the neighborhood mobility of the full population of residents in the city of Stockholm from 1998 to 2012. All the simulation's parameters (e.g., different groups' spatial distribution across the city, incomes, ethnic shares, and households' composition shares) match real distributions for the city of Stockholm for the period under consideration. The conditional logit models' coefficients estimated for each group governs the residential behavior of the households in the simulation.

\section{The groups}

Based on the intersection of the two household dimensions relevant to neighborhood choice identified in prior literature, ethnic background (natives, non-natives, and mixed) and the household composition (singles, singles with children, couples, and couples with children), I define and model the behavior of ten exclusive groups (see Table 1). Whereas household composition reflects the number of persons living in a unique dwelling unit and the presence of children, household ethnicity depends on households' country of origin: for this study non-single households are natives if both members of the couple are Swedish in background, immigrants if both have a foreign origin, and mixed if one has a Swedish origin. As noted in Table 1, Swedish single is the larger group and the group with the higher tendency to move around the city. Furthermore, households with children are the group with the highest disposable income.

\section{Neighborhood mobility}

Conditional logit models describe how individuals select alternatives within a finite, exhaustive, and exclusive set of options, allowing researchers to model systematic taste variation by incorporating both individual and neighborhood characteristics in their estimations [5, 59]. This makes them suitable tools for modeling neighborhood mobility while capturing relevant and heterogeneous aspects of neighborhood choice [29, 49]. Building on key theoretical insights from the literature concerning ERS, I specify a set of behavioral models in which neighborhoods' characteristics and their interaction with households' characteristics, determine neighborhood choices. Neighborhoods' characteristics: current neighborhood or not ("Stay"), the proportion of swedes at neighborhoods ("P-Swed"), neighborhood average income ("NBH-Avg-Inc"), the proportion of renters/owners at neighborhoods ("NBH-Prop-Rent"), neighborhood size ("NBH-size"), and the proportion of single households at neighborhoods ("Prop-Singles"). Interactions: Euclidian distance between the centroid of the current neighborhood and 


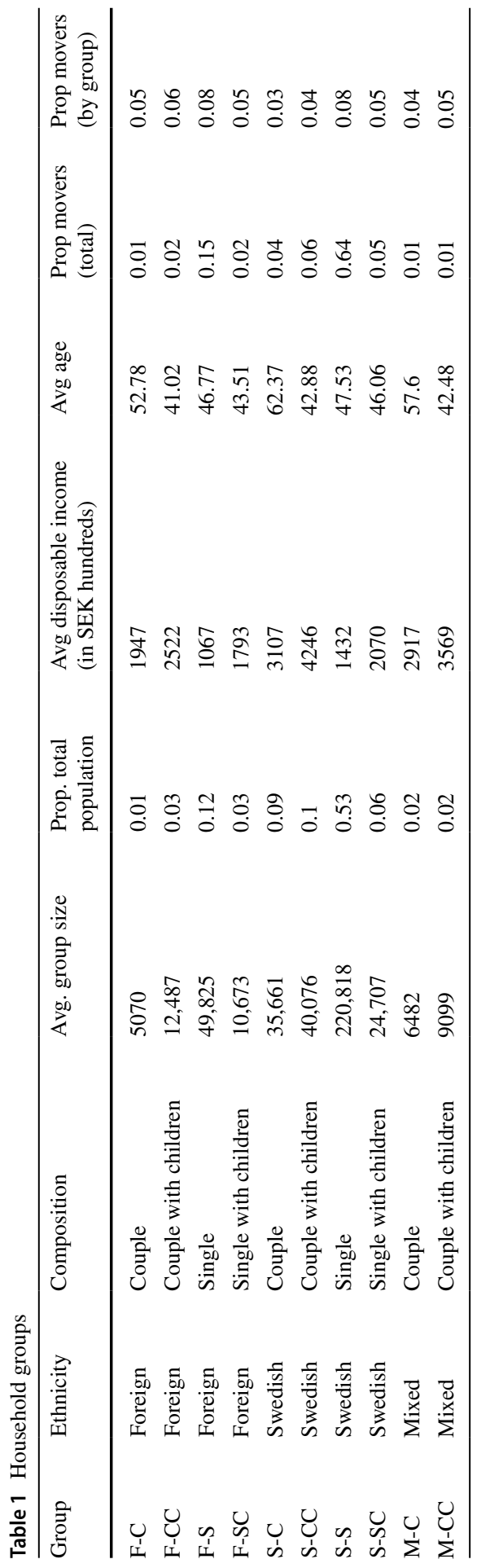


Table 2 SAMS summary statistics

\begin{tabular}{lrrllll}
\hline Statistic & \multicolumn{1}{l}{ Mean } & St. Dev & Min & Pctl. (25) & Pctl. (75) & Max \\
\hline Avg. size & 3693.9 & 2934.5 & 47 & 1380.8 & 5260.5 & 14,240 \\
Avg. income & 2463.5 & 1096.6 & 748 & 1767.6 & 2767.5 & 8367 \\
Avg. age & 45.337 & 5.342 & 26 & 42 & 49 & 67 \\
Avg. prop. Swedes & 0.766 & 0.134 & 0.109 & 0.744 & 0.841 & 0.944 \\
Avg. prop. Renters & 0.506 & 0.259 & 0.000 & 0.306 & 0.712 & 1.000 \\
\hline
\end{tabular}

other neighborhoods' centroids ("H-Dist-NBH"), current neighborhood by the proportion of swedes at neighborhoods ("Stay X P-Swed"), current neighborhood by neighborhood size ("Stay X NBH-size"), current neighborhood by housing ownership - renter or owner ("Stay X Owner"), the absolute difference between the proportion of swedes at current neighborhood and other neighborhoods ("Diff-Share"), the absolute difference between household income and average neighborhoods' income ("SES-Homo"), and household average age by the proportion of swedes at neighborhoods ("Age X P-Swed"). Drawing on Bruch and Mare [10], I specify the following model for each group described above:

$$
p_{i j t+1}\left(Z_{j}, X_{i}, C_{(i)}\right)=\frac{\exp \left(\beta Z_{j t}+\gamma Z_{j t} X_{i t}+\delta D_{i j t}+\theta D_{i j t} Z_{j t}-\ln q_{i j t}+\ln M_{j}+\varphi_{i j t}\right)}{\sum_{k \in C_{i}} \exp \left(\beta Z_{j t}+\gamma Z_{j t} X_{i t}+\delta D_{i k t}+\theta D_{i k t} Z_{k t}-\ln q_{i k t}+\ln M_{k}+\varphi_{i k t}\right)}
$$

where $p_{i j t+1}\left(Z_{j}, X_{i}, C_{(i)}\right)$ denotes the probability that household i selects the neighborhood $\mathrm{j}$ in time $t+1$, conditioned on the observed characteristics on time $t$ of the neighborhood $j\left(Z_{j}\right)$, the observed characteristics of household $i\left(X_{i}\right)$, and the choice set of the household $i\left(C_{(i)}\right)$. $\varphi_{i j t}$ represents the unobserved characteristics of both the neighborhood and the household and follows a type I extreme value (Gumbel) distribution. $\beta, \gamma, \delta$, and $\theta$ are the parameters to be estimated. $M_{j}$ is the number of households living in the neighborhood j. Since households' characteristics $\left(X_{i t}\right)$ are relevant to neighborhood choice but the model estimation does not discriminate among them, I enter them as interaction terms in $\gamma Z_{j t} X_{i t}$. Furthermore, the model specification allows for the possibility that households evaluate their current neighborhoods differently than potential ones by including a dummy variable $D_{i j t}$ (the "Stay" variable in the previous paragraph), where 0 means a different neighborhood and 1 the current one. And finally, given the high computational cost of estimating these discrete choice models, following Jarvis's suggestion [35], I sample 20 percent of the neighborhood alternatives (including the chosen alternative), where $q_{i j t}$ denotes the probability of sample the alternative $\mathrm{j}$ for household $i$.

\section{The data}

I use Swedish longitudinal register data for the whole population of residents in the Stockholm municipality between 1998 and 2012. As previous studies based 
on Swedish data, I define neighborhoods using the Small Area Market Statistics (SAMS). SAMSs are smaller divisions of Swedish municipalities (see polygons in Map 1). In total, the simulation involves 128 SAMSs. Table 2 shows the descriptive statistics of the SAMSs' variables used in the estimation of the conditional logit models and the simulation. The geographical space of the model is circumscribed thus to the Stockholm municipality (see Map 1). In addition to rich information about sociodemographic and geospatial variables, these records contain annual mobility information. In this study, a movement is defined whenever a household changes her SAMS's identification from one year to another as long as the movement has taken place within the circumscribed area. During the conditional logit models' estimation, I exclude from the analysis of those movements which took place inside the same SAMS identification since they did not provide any variation at the neighborhood level. These movements represent around 0.1 percent of all the mobility records.

\section{The simulation procedure}

ERS processes unfold as a result of at least four patterns of movements: (1) stayers, (2) movers, (3) dropouts, and (4) the newly arrived. In the simulation, dropouts and the newly arrived are treated as exogenous events under the assumption their behavior corresponds to different motivations than those of movers and stayers. I include them in the simulation, however, since over time they affect neighborhoods' composition and consequently other households' mobility. Likewise, since each household accounts for a set of members, it might be the case that households split or join, as well. Under the assumption that both behaviors correspond to a different drive than regular residential movements, their behaviors are not modeled but are included as it is reported in the registers. For example, if a household split into two new households from time $t$ to time $t+1$ (e.g., a divorce), those new households will appear in the neighborhoods they moved into in time $t+1$. Or, if two households join from time $t$ to time $t+1$ (e.g., a marriage), they will appear in the neighborhood as indicated in the registers in time $t+1$. Therefore, during the simulation, only the residential behavior of those households who stay or move around the city and do not change their family composition for two consecutive years will be governed by the coefficients of the conditional logit models.

The simulation proceeds as follows:

1. At the beginning of the simulation, households are distributed in the city (Map 1) following households' spatial distribution for the city of Stockholm in 1998. Furthermore, households' and neighborhoods' characteristics are parameterized using Swedish registers for the same year. 
2. Then, every household that stays or moves around the city between the current year and the next, and does not change their family composition, evaluates individually the probability of choosing each neighborhood (including their actual neighborhood) using the conditional model specified in Eq. (1). Using a multinomial sampling based on the predicted probabilities for each of the 128 neighborhoods, each household sample one neighborhood: if the sampled neighborhood is the same, the household chooses to stay, otherwise, she moves into the new one.

3. Once all households have chosen, I remove and add, based on empirical registers, dropouts (for the current year), and newly arrived households (for the next year), respectively. Moreover, households who have split or joined, are updated and placed in the neighborhoods as it is indicated in the registers. ${ }^{2}$

4. After that, I evaluate the level of ERS using the Dissimilarity Index [34] at the household level, taking foreign households as a reference group.

5. For the next year in the simulation, households' attributes (household composition, income, house ownership, age) are updated based on Swedish registers, as well as households' new neighborhood (if they moved) and neighborhood characteristics (ethnic share, socioeconomic status, size) as a result of the residential mobility during the previous year. However, for all the simulations, the parameter for the proportion of rental houses for each neighborhood is constant for all the years and takes the values for the year 1998 .

6. Steps 2-5 are repeated until the year 2012 .

\section{Results}

In this section, I present the study's main results. The first part will focus on the behavioral aspects, the conditional logit models, the second on the macro-patterns of ERS obtained from a set of counterfactual experiments in the simulation model. Finally, the third part centers on opening the black box of the main results.

\section{Behavioral models on neighborhood choice}

Models' estimates are shown in Table 3 for each group. Given the complex interactions specified in the models, I opt to showing their predicted probabilities to get a sense of their behavioral implications and to make them comparable to other studies on neighborhood choices discussed in previous sections. I estimate the same model specification separately for each group considered in the study.

Figures 1 and 2 show the behavioral aspects of all groups. These plots illustrate the effects of some neighborhood-level covariates (while holding others constant) on the probabilities households will select them. Overall, the results are in line with

\footnotetext{
${ }^{2}$ From the total number of households, on average for two consecutive years, $76 \%$ will stay in the same neighborhood, $6.5 \%$ will move around the city, $6.5 \%$ will leave the city, $7 \%$ will arrive at the city, $2 \%$ will split, and $2 \%$ will join in a new household.
} 


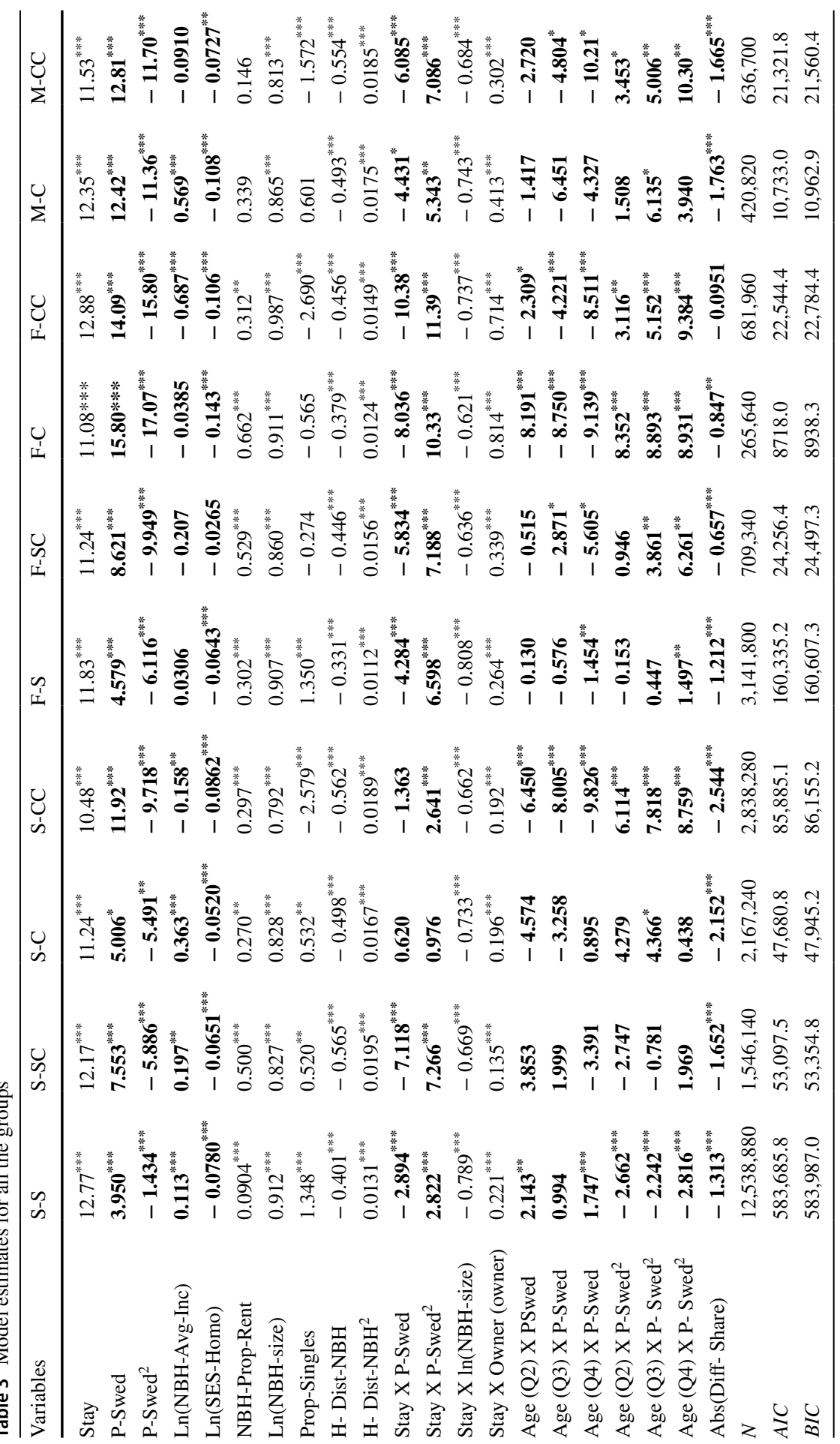




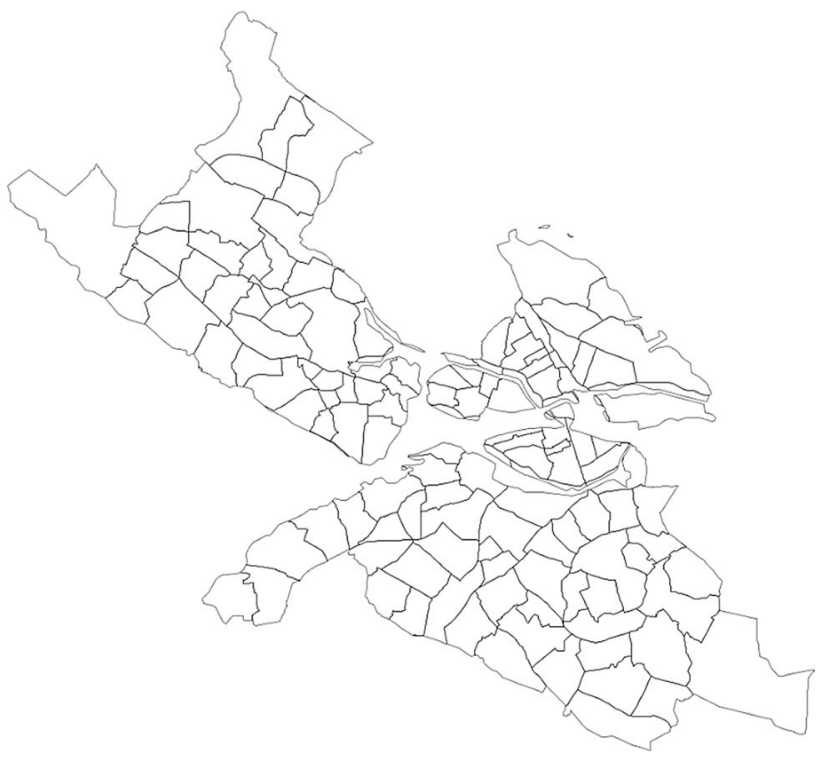

Map 1 SAMS spatial distribution at Stockholm municipality

previous findings in the literature. I find significant differences in the behavioral patterns across groups, but, interestingly, also noteworthy similarities.

Figure 1 shows the main differences. Concerning households' ethnic background, I find that Swedish households are more likely to stay in Swedish neighborhoods compared to foreign households, for whom the effect is far less pronounced, although in the same direction (in panel a of Fig. 1). Similarly, Swedes are more likely to move into Swede-dominated areas than are foreign families, who incline more to move into neighborhoods where they are neither the majority nor the minority (in panel b of Fig. 1). With respect to composition, Swedish couples with children are less likely to stay in non-Swedish neighborhoods than their counterpart singles, but equally likely to move into areas dominated by Swedes. Except for couple-children households, who prefer to stay in more mixed neighborhoods, foreign households do not show significant differences as to their structures when it comes to the neighborhoods' ethnic compositions.

I specify the proportion of single households in neighborhoods in the conditional logit model as a proxy to capture certain neighborhood characteristics which may be more desirable to single households than to non-singles [33, 42]. As indicated in panel d of Fig. 1, both foreign and Swedish singles exhibit higher probabilities of moving into neighborhoods with higher shares of singles, whereas couples and couple with children households, in general, show the opposite tendency.

Surprisingly, households do display some similar mobility patterns regardless of ethnic background or composition. As Fig. 2b and d show, socioeconomic-ethnic homophily channels part of their moving-in behavior, creating a clear bias, especially for Swedish families, in choosing neighborhoods with similar ethnic shares and socioeconomic characteristics. Finally, households are more inclined to choose 
(a) Staying at NBH

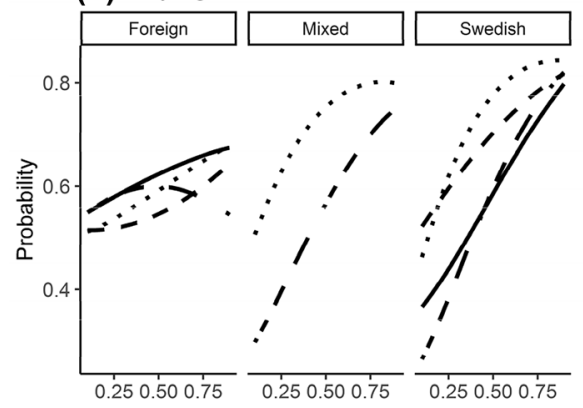

Proportion Swedish households at NBH

(c) NBH Avg. Income

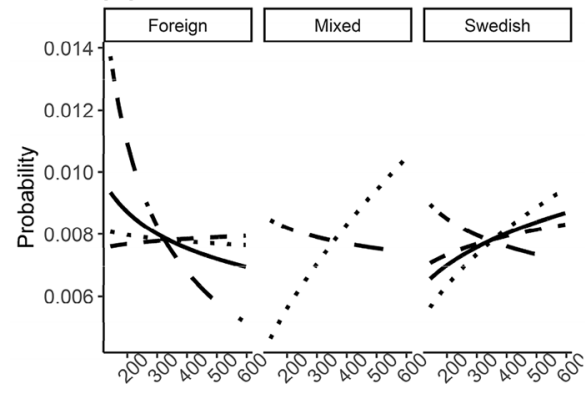

Mean NBH income (in thousand Swedish kronor)

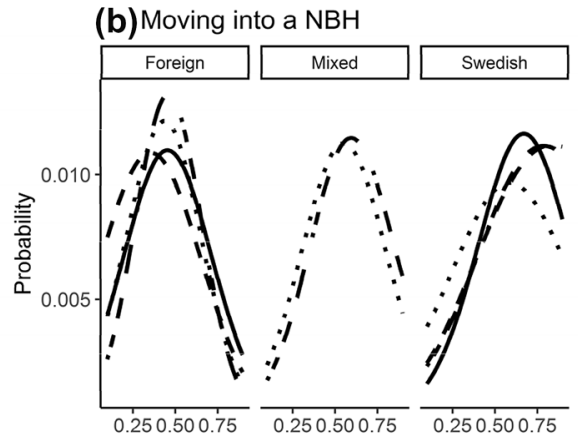

Proportion Swedish households at $\mathrm{NBH}$

(d) Prop. Single Households

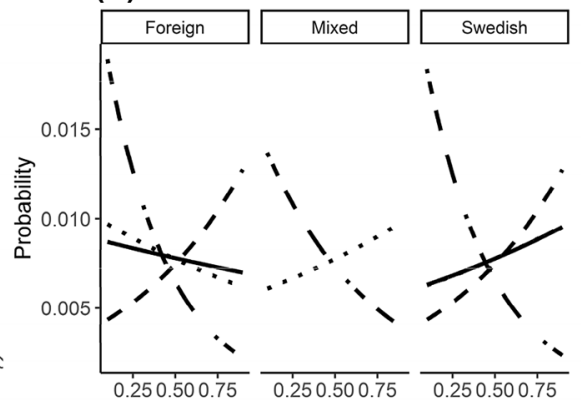

Proportion single households at $\mathrm{NBH}$

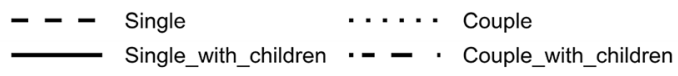

Fig. 1 Predicted probabilities of choosing a Neighborhood: differences

nearby neighborhoods, as well as places where the proportion of rented houses is higher.

\section{Groups' contributions within a dynamic perspective}

While in the previous section I have shown major residential mobility patterns of different groups based on ethnic background and household composition, here I present their main macro-level implications for ERS dynamics within an empirically calibrated simulation framework. More specifically, this part of the analysis seeks to evaluate to what extent each group contributes to modifying segregation.

My analytical strategy involves two steps. The first focuses on implementing a basic simulation model. In this model, households' behavior follows the conditional logit model parameters estimated in the previous stage. This model also acts as a reference line for quantifying how much segregation levels change within a set of counterfactual simulations. Given the importance of this analysis, I perform several 
(a) Rented Houses

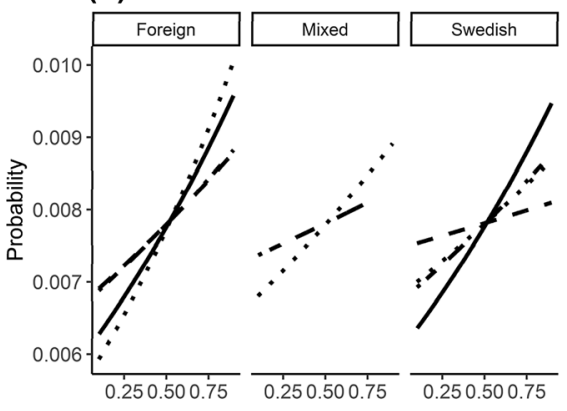

Proportion rented houses at $\mathrm{NBH}$

(c) Distance

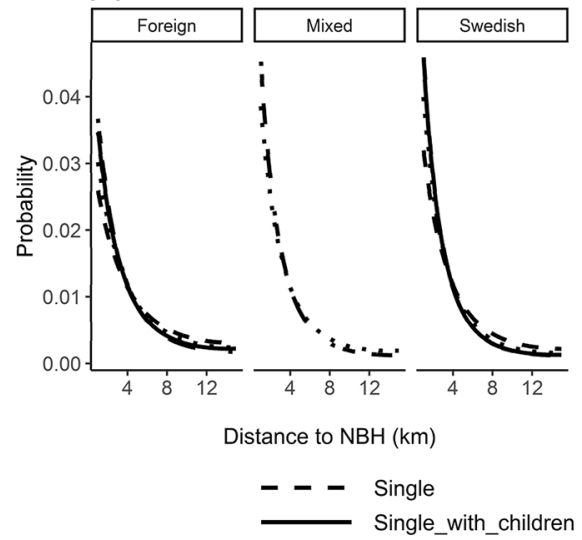

(b) Household Income

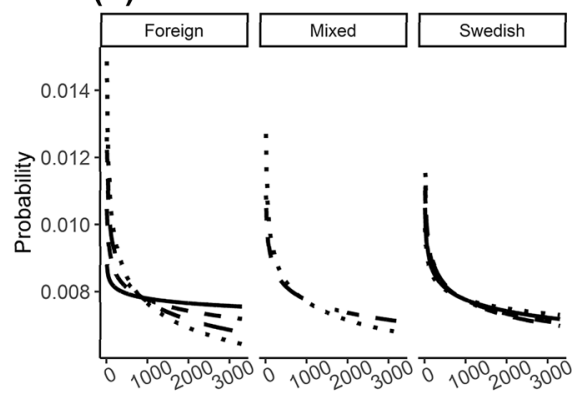

| Household income - mean NBH income |

(d) NBH Ethnic Homophily

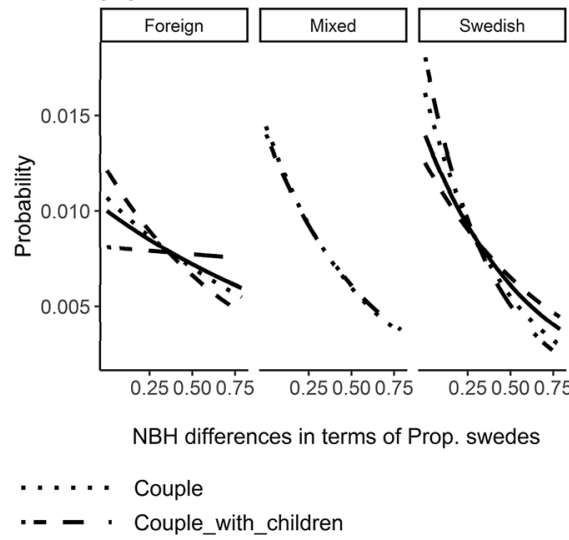

Fig. 2 Predicted probabilities of choosing a Neighborhood: similarities

external validity tests to evaluate whether the basic model reliably mimics actual patterns of segregation at different levels. The results of this analysis show a high correspondence between the basic model results and actual levels of segregation. ${ }^{3}$

The second step queries the basic model: the interventions. In particular, I seek to evaluate several counterfactual scenarios under one specific intervention: households' blind choices concerning neighborhoods' ethnic and socioeconomic features. Namely, what would the level of segregation have been had one specific group considered neither ethnic share nor socio-economic aspects in its neighborhood choice, maintaining other groups' behavior as in the basic model? Thus, I run a set of experiments wherein I compare, for all groups, the long-term results obtained from the basic model with the long-term results from the intervened models. The difference between the segregation levels produced by the basic and the intervened model therefore quantify groups' contribution to changing levels of segregation due to ethnic and socioeconomic factors.

\footnotetext{
3 All the external validation tests are shown in the appendix in ESM.
} 
Fig. 3 Simulation Results. $Y$-axis shows the average percentage change in the Dissimilarity Index in reference to the results obtained on the basic model. $X$-axis shows the effect when all the groups are intervened and also disaggregated results by composition and ethnicity

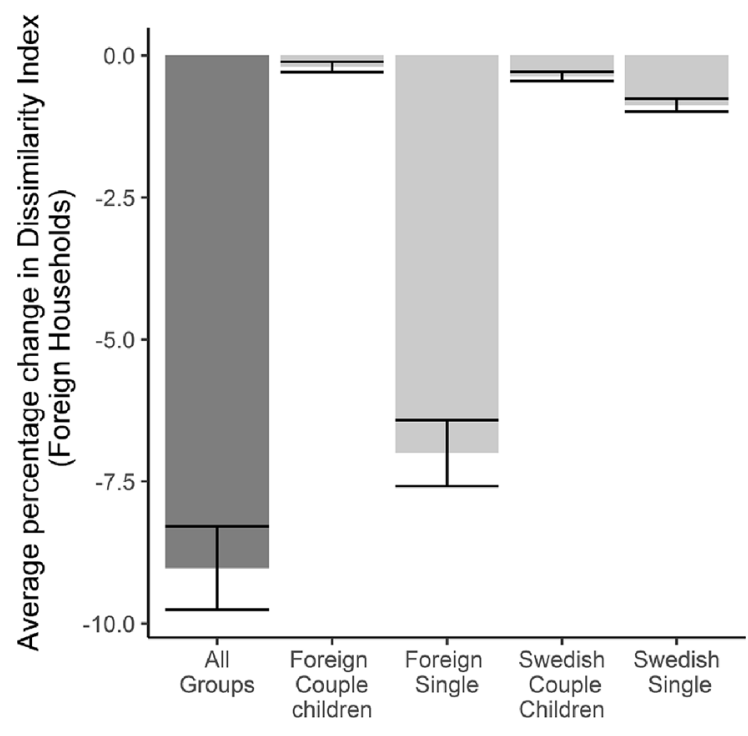

Each intervention consists of multiplying by zero (deactivating) all coefficients in the behavioral choice related to ethnic and socioeconomic aspects of the neighborhood choice for each specific intervened group. Coefficients in bold in Table 3 were manipulated for all the interventions. I then apply a factorial experiment design between groups and interventions to evaluate comparatively the effect of each group on ERS.

The grounds for the interventions lie in the identification of the interaction between the households' ethnic-socioeconomic character and neighborhoods' ethnic-socioeconomic status as the key driver of ERS. They stand at the heart of both "the spatial assimilation theory" and "the place stratification model", respectively, two of the most mainstream explanations for ERS [12]. As Figs. 1 and 2 have shown, these variables capture the idea that households tend to move into neighborhoods on the basis of ethnic shares and socioeconomic status, conditioned on their own ethnic background, composition, and disposable income. Accordingly, a blind choice as to those aspects should remove any segregation-promoting mobility for each group. Therefore, I predict a drop in segregation levels following those factors' deactivation. However, it is uncertain which group would exhibit a deeper fall: which group would contribute the most to changing levels of ERS?

Given that interventions on certain groups did not reveal significant variations during the computational experiments, compared with the basic model, I display only the results of interventions on those that did: foreign singles, foreign couples with children, Swedish singles, and Swedish couples with children.

Figure 3 depicts the main results of our computational experiments. ${ }^{4}$ As expected, for all the interventions implemented (ethnic-socioeconomic aspects of

\footnotetext{
${ }^{4}$ The figure shows the average results of twenty simulations for each intervention and for the basic model.
} 


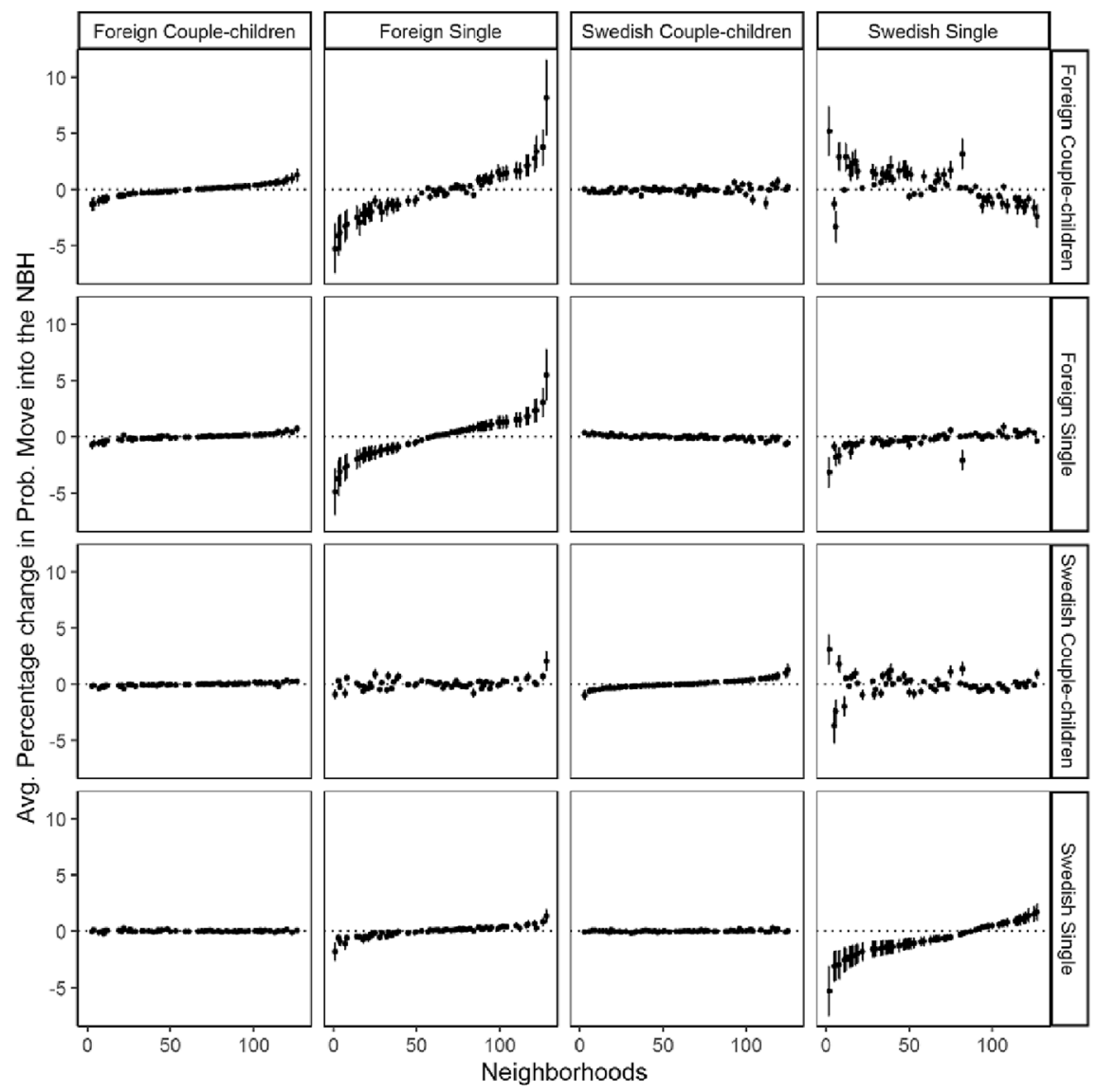

Fig. 4 Feedback effect of group mobility. The plot shows the average percentage change in the movein probabilities of groups (rows) when one group moves (columns). The $x$-axis shows neighborhoods ordered by percentage change for each column

neighborhood choice being deactivated), the level of segregation decreases. In terms of household composition, interventions in single households show a greater effect reducing segregation. However, the intervention upon foreign singles reduced segregation by more than seven percentage points, a substantially greater effect compared with those on the other groups. Results in Fig. 3 hold even when ERS is measured at the individual level instead of the household level, with alternative spatial segregation indices [51], and with a random distribution of newcomers into the city. In addition, I also relax the assumption that households' house ownership matters for their residential mobility by running a sensitivity analysis where the coefficient "Stay $\mathrm{X}$ Owner" is multiplied by zero, and I get the same patterns. A more detailed sensitivity analysis is shown in the appendix.

These results in Fig. 3 show that how foreign singles move across the city has a more significant impact on positively changing ERS (when intervention removes 


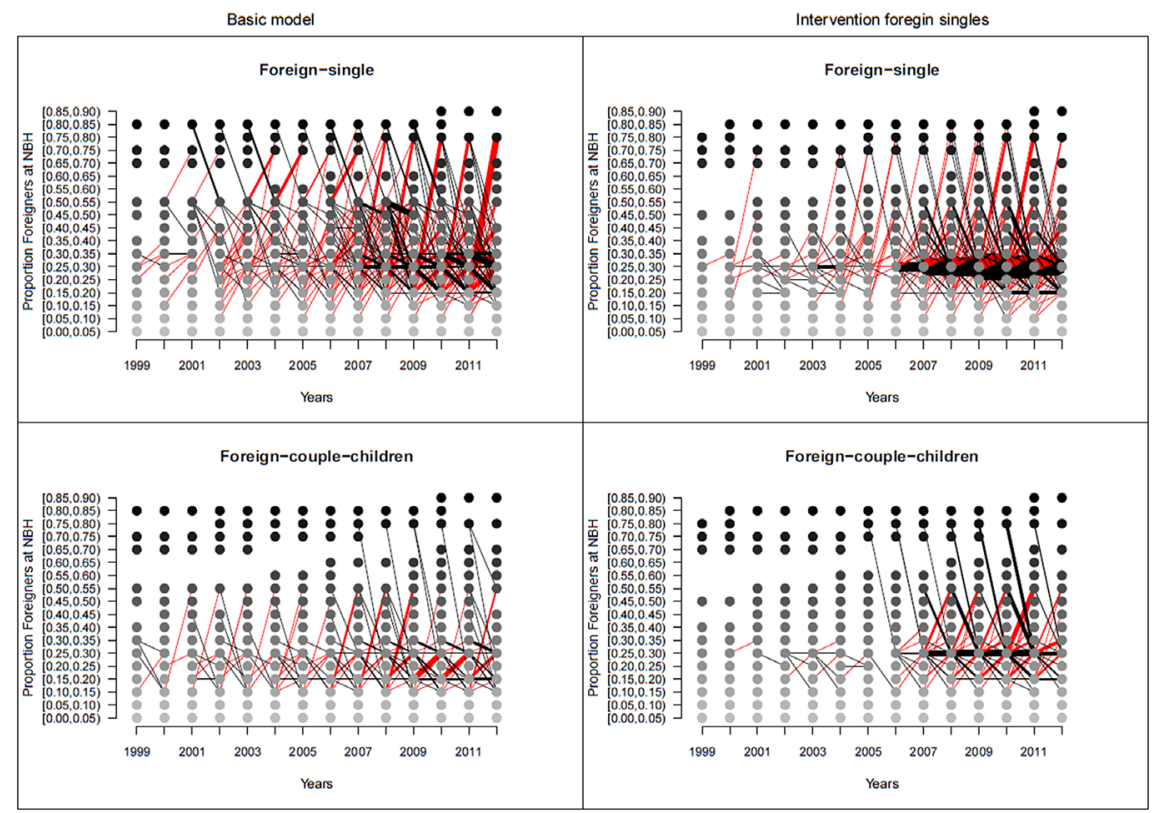

Fig. 5 Cumulative inter-neighborhood mobility for single and couple-children foreigners. The $y$-axis shows the neighborhoods clustered according to the proportion of foreigners, from higher proportions (black circles) to lower proportions (grey circles). The $x$-axis show the years. The thickness of the lines measures the cumulative amount of flow between clustered neighborhoods across the years (in reference to the year 1998), whereas the color whether these movements are segregation-promoting (red lines) or integration promoting (black lines). The first column (Basic Model) depicts the results for the basic model while the second (Intervention) for the simulations in which the ethnic-socioeconomic aspects of neighborhood choice are deactivated only for foreign-singles

their segregation-promoting behavior from the model, segregation drops) relative to all other groups. However, what Fig. 3 does not tell us is why and how this group's mobility pattern should be more determinant. The following section aims to shed some light on this point, analyzing the processes triggered under a foreign single group intervention.

\section{Unveiling the process}

This section aims at explaining why foreign single households contribute the most to changing levels of ERS. My analytical approach consists of comparing the results of the basic model with the foreign single intervention in three different levels: (1) the feedback effect between and among groups, (2) the cumulative inter-neighborhood mobility flow of groups, and (3) the typical patterns of inter-neighborhood mobility among groups.

Drawing on Schelling's approach to analyzing dynamic systems [55], I evaluate how the mobility of groups influences the probabilities of other groups choosing 


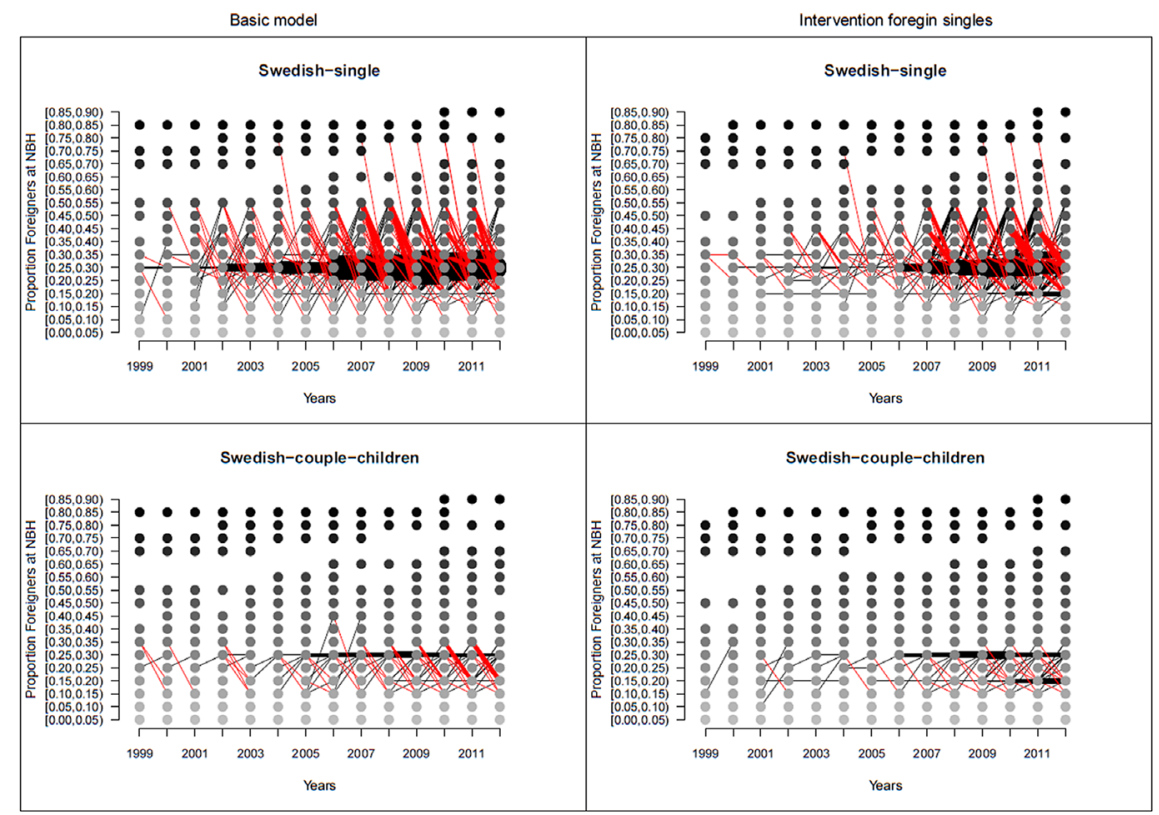

Fig. 6 Cumulative inter-neighborhood mobility for single and couple-children Swedes. The $y$-axis shows the neighborhoods clustered according to the proportion of foreigners, from higher proportions (black circles) to lower proportions (grey circles). The $x$-axis show the years. The thickness of the lines measures the cumulative amount of flow between clustered neighborhoods across the years (in reference to the year 1998), whereas the color whether these movements are segregation-promoting (red lines) or integration promoting (black lines). The first column (Basic Model) depicts the results for the basic model while the second (Intervention) for the simulations in which the ethnic-socioeconomic aspects of neighborhood choice are deactivated only for foreign-singles

future neighborhoods. Thus, I isolate this effect by evaluating how the mobility of one group affects next-year mobility patterns for the same and for other groups.

Figure 4 shows the results of this analysis. By looking at the diagonal of Fig. 4, we find that all groups display a considerable self-reinforcement effect: when they move, the probabilities of same-group selecting the same neighborhoods the next year increase.

Overall, this effect is stronger for foreign than for Swedish households and, within foreign households, stronger still for single ones. Conversely, Swedish households expose a different pattern across household types. For example, neighborhoods that have become less attractive to foreign and Swedish singles because of the movement of Swedish singles become more attractive to Swedish couple-children households.

One way of evaluating the aggregated implications of these feedback effects on ERS is by examining how inter-neighborhood mobility evolves, that is to say, how residential mobility between neighborhoods increases year after year. Since mapping the inter-mobility of 128 neighborhoods would have been uninformative, I cluster them in 20 groups according to their shares of foreigners. 
Figures 5 and 6 illustrate this analysis. In Fig. 5, the results of the basic model (first column) show that single- and to a lesser extent couple-children foreign households gradually increase their transit from neighborhoods with lower shares of foreigners to neighborhoods with higher shares (red lines). This mobility pattern gradually increases segregation by reducing the proportion of foreigners in native neighborhoods and at the same time increasing the proportion of foreigners in segregated neighborhoods. Interestingly, under the foreign single intervention (second column in Fig. 5), foreign singles drastically reduce their mobility from less to more immigrant-dense neighborhoods (thinner red lines), instead increasing their inter-neighborhood mobility between neighborhoods with the same share of foreigners (thicker black lines). Couple-children foreigners follow a similar pattern.

On the other hand, Swedish households reveal the opposite pattern, as Fig. 6 makes clear. In the basic model (first column), Swedes primarily move between Swedish neighborhoods (black lines). Yet, from the year 2006 onwards, they progressively start moving from higher-foreign-share neighborhoods to lower ones (red lines): the white flight [7]. The foreign single intervention (second column in Fig. 6), however, significantly attenuates the white flight effect, reflected in the thickness and number of red lines in the plot.

In general, foreign households' mobility, concretely single ones', show a strong feedback effect in terms of neighborhoods' destinations, leading them increasingly to move into more segregated places. This trend subsequently triggered white flight, amplifying even more the pattern of segregation. All in all, the concatenation of both forces contributes sequentially to raising the level of ERS. Nevertheless, the fact that none of the interventions carried out on Swedish households has had a stronger effect on changing segregation suggests their contribution has only a marginal effect compared to that of foreigners.

At this point of the analysis, it is puzzling why Swedish households, who produce white flight and white avoidance (as indicated in Figs. 1 and 2), do not significantly change the level of ERS following alteration of their mobility patterns. Figure 7 presents some insights into this. The plot shows the most typical flow patterns among neighborhoods for foreign and Swedish single households under the basic model. ${ }^{5}$

The plot shows that foreign single households exhibit a more heterogeneous mobility pattern in terms of neighborhoods' ethnic composition, moving between highly segregated neighborhoods, and in both segregating and desegregating directions (crossing red and black lines). On the other hand, Swedish single households' mobility takes place overwhelmingly across Swedish neighborhoods. Most interestingly, despite this, their mobility flow interleaves segregation-promoting (red lines) and integration-promoting (black lines). That is, Swedish-households' inter-mobility patterns cancel out their contribution to increasing segregation over the years. This finding recognizes Swedish mobility patterns regarding ERS much more as

\footnotetext{
5 For each two consecutive years, I evaluate the proportion of movers between clustered neighborhoods for each specific group. The plots show the interquartile rate of this distribution across the years. The typical patterns shown in Fig. 7 hold for different family compositions and for all interventions.
} 


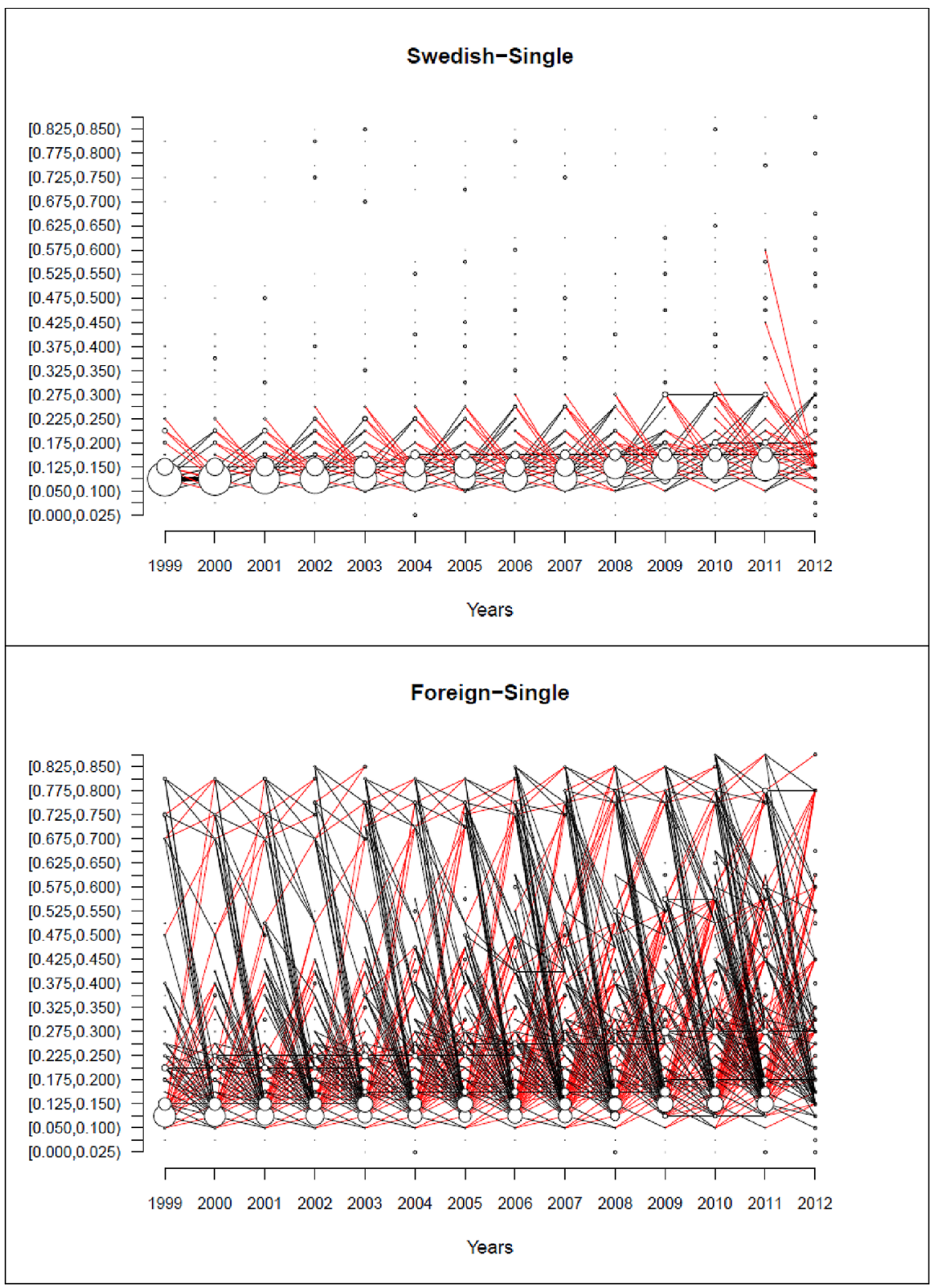

Fig. 7 Typical inter-neighborhood mobility patterns for singles. The y-axis shows the neighbor-hoods clustered according to the proportion of foreigners, from lower proportions (bottom side) to higher proportions (upper side). The $x$-axis represents the years. The size of the circle measures the number of movers. The thickness of the lines measures the amount of flow between grouped neigh-borhoods. The color of the lines represents whether these movements are segregation-promoting (red lines) or integration promoting (black lines) 
segregation-keeping than segregation-changing. Furthermore, it explains why, in all the interventions carried out on this group (see Fig. 3), the level of segregation did not drop significantly.

\section{Conclusion and discussion}

ERS is a social phenomenon brought about by the continuous and interdependent inter-neighborhood mobility of several ethnic-socioeconomic groups over time. Understanding groups' contributions to changing segregation requires evaluating not only what determines groups' mobility at the micro-level, but also how their actual mobility eventually affects macro-segregation patterns within specific empirically grounded initial conditions. Previous studies, on one side, have indirectly inferred groups' contributions to ERS from individual behavioral models, omitting crucial dynamic aspects of residential mobility. Dynamic studies, on the other side, have explored the implications of some micro-foundation rules within highly stylized environments, overlooking key empirical aspects. This study is an effort to reconcile both approaches' strengths.

Based on the two main determinants of households' neighborhood mobility at the micro-level, ethnic background, and household composition, I define and model ten different groups' behavior by estimating a set of conditional logit models using register data for the city of Stockholm. Then, I implement a large-scale empirically calibrated simulation model on ERS to evaluate these groups' relative contributions to segregation change. At the micro-level, the results are in line with previous findings in the literature on segregation, providing the groups' decision-rules with high solvency as regards evaluating their actions' macro-implications. Both ethnicity and family composition [26, 42] help explaining heterogeneous patterns of neighborhood choice.

At the dynamic side, I conduct a set of computational experiments wherein I counterfactually evaluate the effects of ethnic and socioeconomic aspects in neighborhood choice for each group. I find foreign singles to be the most segregation-promoting group. Unlike other households, their neighborhood mobility shows a strong self-reinforcement in-group effect with regard to choosing future neighborhoods. This feedback effect on this group yields a progressively increasing flow from lowimmigrant neighborhoods to high-immigrant neighborhoods. Ultimately, this tendency fosters segregation because more foreign households move into segregated neighborhoods and, simultaneously, more native households leave segregated neighborhoods. However, Swedes did not significantly contribute to changing levels of segregation since their predominant inter-neighborhood mobility takes place within highly Swedish-dominated neighborhoods.

This paper contributes to the segregation literature in two key aspects. First, it shows the importance of simulation models to understanding unobvious ways in which individual actions relate to macro-patterns of segregation. Even though foreign single groups contribute more significantly to raising the level of ERS: (1) they do not show strong patterns of leaving or moving into neighborhoods due to neighborhoods' ethnic composition, as happens with Swedish households in general, (2) 
they are not the largest group, making up 12 percent of the population compared with Swedish singles (who represent 51 percent), and (3) their movements represent 15 percent of the total number of movements, while Swedish singles represent 64 percent. Second, this study not only provides quantitative results of the computational experiments carried out, but also prises open the black box of the unfolded machinery- the mechanisms-for each intervention. Mapping this concatenation of events provides a more precise account of the processes triggered by specific interventions in the model and, consequently, makes salient the effects of any prospective policy interventions.

These findings show that, under realistic initial conditions, foreign singles' mobility is much more segregation-promoting than other groups'. Some clarifications, however, necessitate closer elaboration. Even though evidence suggests that landlords negatively prejudge single households in the housing market [42], leading, consequently, to far greater discrimination than their non-single counterpart face, I was not able to distinguish those discriminatory practices in my behavioral models. Nonetheless, the data used in this study allow me to observe how both factors operate together in shaping households' mobility. In this vein, we may think of my simulation approach as a pairing-up system, matching groups with neighborhoods based on some theoretically relevant characteristics on either side.

From a policy implication perspective, my results suggest that foreign single households are the most efficient target group for any integration initiative. This implication is particularly relevant for Sweden, where approximately half the population corresponds to a single-person household. Other involvement would focus on reversing the residential flow of foreign singles, either by promoting their mobility into Swedish-dominated areas or by creating one-person dwelling units in strategic residential areas to foster greater desegregation.

Simulation models are powerful tools for understanding social systems, and when set within realistic environments, become reliable instruments for exploring impacts of potential interventions. Modelers must go further than simple quantification of models' results, investigating how interventions in the model affect its dynamics over time. The complexities of ERS demand analysis of more dimensions that may also be critical to our understanding of segregation.

Supplementary Information The online version contains supplementary material available at https://doi. org/10.1007/s42001-021-00136-6.

Funding Open access funding provided by Linköping University. This work was suppoerted by Swedish Research Council (Grant no. 445-2013-7681).

\section{Declarations}

Conflict of Interest On behalf of all authors, the corresponding author states that there is no conflict of interest.

Open Access This article is licensed under a Creative Commons Attribution 4.0 International License, which permits use, sharing, adaptation, distribution and reproduction in any medium or format, as long as you give appropriate credit to the original author(s) and the source, provide a link to the Creative Commons licence, and indicate if changes were made. The images or other third party material in this article 
are included in the article's Creative Commons licence, unless indicated otherwise in a credit line to the material. If material is not included in the article's Creative Commons licence and your intended use is not permitted by statutory regulation or exceeds the permitted use, you will need to obtain permission directly from the copyright holder. To view a copy of this licence, visit http://creativecommons.org/licen ses/by/4.0/.

\section{References}

1. Anderson, P. (1972). More is different. Science, 177, 393-396.

2. Andersson, R. (2003). Settlement dispersal of immigrants and refugees in Europe: Policy and outcomes. Vancouver: Vancouver Centre of Excellence.

3. Andersson, R. (2006). 'Breaking segregation' - rhetorical construct or effective policy? The case of the metropolitan development initiative in Sweden. Urban Studies, 43(4), 787-799. https://doi.org/ 10.1080/00420980600597608

4. Arvidsson, M., Collet, F., \& Hedström, P. (2021). The Trojan-horse mechanism: How networks reduce gender segregation. Science Advances, 7(16), eabf6730. https://doi.org/10.1126/sciadv.abf67 30

5. Ben-Akiva, M. E., \& Lerman, S. R. (1985). Discrete choice analysis: Theory and application to travel demand. MIT Press.

6. Benenson, I., Omer, I., \& Hatna, E. (2002). Entity-based modeling of urban residential dynamics: The case of Yaffo, Tel Aviv. Environment and Planning B: Planning and Design, 29(4), 491-512. https://doi.org/10.1068/b1287

7. Bråmå, A. (2006). "White flight"? The production and reproduction of immigrant concentration areas in Swedish Cities, 1990-2000. Urban Studies, 43, 1127-1146. https://doi.org/10.2307/43201 626

8. Bruch, E., \& Atwell, J. (2015). Agent-based models in empirical social research. Sociological Methods \& Research, 44(2), 186-221. https://doi.org/10.1177/0049124113506405

9. Bruch, E. E., \& Mare, R. D. (2006). Neighborhood choice and neighborhood change. American Journal of Sociology, 112(3), 667-709. https://doi.org/10.1086/507856

10. Bruch, E. E., \& Mare, R. D. (2012). Methodological issues in the analysis of residential preferences, residential mobility, and neighborhood change. Sociological Methodology, 42(1), 103154. https://doi.org/10.1177/0081175012444105

11. Charles, C. Z. (2000). Neighborhood racial-composition preferences: Evidence from a multiethnic metropolis. Social Problems, 47(3), 379-407. https://doi.org/10.2307/3097236

12. Charles, C. Z. (2003). The dynamics of racial residential segregation. Annual Review of Sociology, 29(1), 167-207. https://doi.org/10.1146/annurev.soc.29.010202.100002

13. Clark, W. A. V. (2002). Ethnic preferences and ethnic perceptions in multi-ethnic settings. Urban Geography, 23(3), 237-256. https://doi.org/10.2747/0272-3638.23.3.237

14. Coenen, A., Verhaeghe, P.-P., \& Van de Putte, B. (2019). Ethnic residential segregation: A family matter? An integration of household composition characteristics into the residential segregation literature. European Journal of Population. https://doi.org/10.1007/s10680-018-09514-9

15. Coulter, R., \& Scott, J. (2015). What motivates residential mobility? Re-examining self-reported reasons for desiring and making residential moves. Population, Space and Place, 21(4), 354371. https://doi.org/10.1002/psp.1863

16. Craig, P., Dieppe, P., Macintyre, S., Michie, S., Nazareth, I., Petticrew, M., \& Medical Research Council Guidance. (2008). Developing and evaluating complex interventions: the new Medical Research Council guidance. BMJ (Clinical Research Ed.), 337, a1655. https://doi.org/10.1136/ bmj.a1655

17. Crooks, A. T. (2010). Constructing and implementing an agent-based model of residential segregation through vector GIS. International Journal of Geographical Information Science, 24(5), 661-675. https://doi.org/10.1080/13658810903569572

18. Crowder, K. (2000). The racial context of white mobility: An individual-level assessment of the white flight hypothesis. Social Science Research, 29(2), 223-257. https://doi.org/10.1006/ssre. 1999.0668 
19. De la Roca, J., Ellen, I. G., \& O’Regan, K. M. (2014). Race and neighborhoods in the 21st century: What does segregation mean today? Regional Science and Urban Economics, 47, 138-151. https://doi.org/10.1016/J.REGSCIURBECO.2013.09.006

20. Epstein, J. M. (2006). Generative social science: Studies in agent-based computational modeling. Princeton University Press.

21. Feitosa, F. F., Le, Q. B., \& Vlek, P. L. G. (2011). Multi-agent simulator for urban segregation (MASUS): A tool to explore alternatives for promoting inclusive cities. Computers, Environment and Urban Systems, 35(2), 104-115. https://doi.org/10.1016/J.COMPENVURBSYS.2010.06.001

22. Feitosa, F. F., Le, Q. B., Vlek, P. L. G., Monteiro, M. V. A., \& Rosemback, R. (2012). Countering Urban Segregation In Brazilian cities: Policy-oriented explorations using agent-based simulation. Environment and Planning B: Planning and Design, 39(6), 1131-1150. https://doi.org/10. $1068 / \mathrm{b} 38117$

23. Frankenberg, E. (2013). The role of residential segregation in contemporary school segregation. Education and Urban Society, 45(5), 548-570. https://doi.org/10.1177/0013124513486288

24. Frey, W. H. (1979). Central city white flight: Racial and nonracial causes. American Sociological Review, 44(3), 425. https://doi.org/10.2307/2094885

25. Gilbert, N. (2008). Agent-based models. Sage Publications.

26. Goyette, K., Iceland, J., \& Weininger, E. (2014). Moving for the kids: Examining the influence of children on white residential segregation. City \& Community, 13(2), 158-178. https://doi.org/10. 1111 cico. 12058

27. Granovetter, M. (1978). Threshold models of collective behavior. American Journal of Sociology, 83, 1420-1443.

28. Hansen, L. P., \& Heckman, J. J. (1996). The empirical foundations of calibration. Journal of Economic Perspectives, 10(1), 87-104. https://doi.org/10.1257/jep.10.1.87

29. Hedman, L., van Ham, M., \& Manley, D. (2011). Neighbourhood Choice And Neighbourhood Reproduction. Environment and Planning A: Economy and Space, 43(6), 1381-1399. https://doi. org/10.1068/a43453

30. Hedström, P. (2005). Dissecting the social. Cambridge University Press. https://doi.org/10.1017/ CBO9780511488801

31. Homer, J. B., \& Hirsch, G. B. (2006). System dynamics modeling for public health: Background and opportunities. American Journal of Public Health, 96(3), 452-458. https://doi.org/10.2105/ AJPH.2005.062059

32. Huang, Q., Parker, D. C., Filatova, T., \& Sun, S. (2014). A review of urban residential choice models using agent-based modeling. Environment and Planning B: Planning and Design, 41(4), 661689. https://doi.org/10.1068/b120043p

33. Iceland, J., Goyette, K. A., Nelson, K. A., \& Chan, C. (2010). Racial and ethnic residential segregation and household structure: A research note*. Social Science Research, 39(1), 39-47. https://doi. org/10.1016/j.ssresearch.2009.06.006

34. James, D., \& Taeuber, K. (1985). Measures of segregation. Sociological Methodology, 15, 1-32.

35. Jarvis, B. F. (2018). Estimating multinomial logit models with samples of alternatives. Sociological Methodology. https://doi.org/10.1177/0081175018793460

36. Krysan, M., \& Crowder, K. (2017). Cycle of segregation: Social processes and residential stratification. Russell Sage Foundation.

37. Kydland, F. E., \& Prescott, E. C. (1996). The computational experiment: an econometric tool. Journal of Economic Perspectives, 10(1), 69-85. https://doi.org/10.1257/jep.10.1.69

38. León-Medina, F. J. (2017). Analytical sociology and agent-based modeling: Is generative sufficiency sufficient? Sociological Theory, 35(3), 157-178. https://doi.org/10.1177/0735275117725766

39. Logan, J. R., Minca, E., \& Adar, S. (2012). The geography of inequality: Why separate means unequal in American Public schools. Sociology of Education. https://doi.org/10.1177/0038040711 431588

40. Macy, M., \& van de Rijt, A. (2006). Ethnic Preferences And Residential Segregation: Theoretical explorations beyond detroit. The Journal of Mathematical Sociology, 30(3-4), 275-288. https://doi. org/10.1080/00222500500544086

41. Mahdavi Ardestani, B., O’Sullivan, D., \& Davis, P. (2018). A multi-scaled agent-based model of residential segregation applied to a real metropolitan area. Computers, Environment and Urban Systems, 69, 1-16. https://doi.org/10.1016/J.COMPENVURBSYS.2017.11.002

42. Marsh, K., \& Iceland, J. (2010). The racial residential segregation of black single adults living alone. City \& Community, 9(3), 299-319. https://doi.org/10.1111/j.1540-6040.2010.01338.x 
43. McFadden, D. (1978). Modelling the choice of residential location. In A. Karlqvist, F. Snickars, \& J. Weibull (Eds.), Spatial interaction theory and planning models (pp. 75-96). North Holland.

44. Morrison, M., \& Morgan, M. (1999). Models as mediating instruments. In M. Morgan, \& M. Morrison (Eds.), Models as mediators. Perspectives on natural and social science (pp. 10-37). Cambridge University Press.

45. Müller, T. S., Grund, T. U., \& Koskinen, J. H. (2018). Residential segregation and 'ethnic flight' vs. 'ethnic avoidance' in Sweden. European Sociological Review, 34(3), 268-285. https://doi.org/10. 1093/esr/jcy010

46. Tunström, M., \& Wang, S. (2019). The segregated city: A Nordic overview. Nordic Council of Ministers.

47. OECD. (2019). Migrant and refugee integration in Stockholm. A Scoping Note. Regional Development Series.

48. Owens, A. (2016). Inequality in children's contexts. American Sociological Review, 81(3), 549-574. https://doi.org/10.1177/0003122416642430

49. Quillian, L. (2010). Race and class in neighborhood mobility: a conditional logit model of neighborhood migration. In Population association of America 2010. Annual meeting program, Dallas, Texas.

50. Rathelot, R., \& Safi, M. (2014). Local ethnic composition and natives' and immigrants' geographic mobility in France, 1982-1999. American Sociological Review, 79(1), 43-64. https://doi.org/10. $1177 / 0003122413514750$

51. Reardon, S. F., \& O’Sullivan, D. (2004). 3. Measures of spatial segregation. Sociological Methodology, 34(1), 121-162. https://doi.org/10.1111/j.0081-1750.2004.00150.x

52. Rossi, P. (1955). Why families move: A study in the social psychology of urban residential mobility. Free Press.

53. Sariaslan, A., Långström, N., D’Onofrio, B., Hallqvist, J., Franck, J., \& Lichtenstein, P. (2013). The impact of neighbourhood deprivation on adolescent violent criminality and substance misuse: A longitudinal, quasi-experimental study of the total Swedish population. International Journal of Epidemiology, 42(4), 1057-1066. https://doi.org/10.1093/ije/dyt066

54. Schelling, T. C. (1971). Dynamic models of segregation. The Journal of Mathematical Sociology, 1(2), 143-186.

55. Schelling, T. C. (1978). Micromotives and macrobehavior. Norton.

56. Semyonov, M., \& Glikman, A. (2009). Ethnic residential segregation, social contacts, and antiminority attitudes in European societies. European Sociological Review, 25(6), 693-708. https://doi. org/10.1093/esr/jen075

57. Semyonov, M., Glikman, A., \& Krysan, M. (2007). Europeans' preference for ethnic residential homogeneity: Cross-national analysis of response to neighborhood ethnic composition. Social Problems, 54(4), 434-453. https://doi.org/10.1525/sp.2007.54.4.434

58. Thomas, M., \& Moye, R. (2015). Race, class, and gender and the impact of racial segregation on black-white income inequality. Sociology of Race and Ethnicity, 1(4), 490-502. https://doi.org/10. $1177 / 2332649215581665$

59. Train, K. (2009). Discrete choice methods with simulation. Cambridge University Press.

60. Watts, D. J. (2014). Common sense and sociological explanations. American Journal of Sociology, 120(2), 313-351. https://doi.org/10.1086/678271

61. White, K., \& Borrell, L. N. (2011). Racial/ethnic residential segregation: Framing the context of health risk and health disparities. Health \& Place, 17(2), 438-448. https://doi.org/10.1016/j.healt hplace.2010.12.002

62. Windrum, P., Fagiolo, G., \& Moneta, A. (2007). Empirical validation of agent-based models: Alternatives and prospects. Journal of Artificial Societies and Social Simulation, 10(2), 8.

63. Xie, Y., \& Zhou, X. (2012). Modeling individual-level heterogeneity in racial residential segregation. Proceedings of the National Academy of Sciences, 109(29), 11646-11651. https://doi.org/10. 1073/pnas.1202218109

64. Yin, L. (2009). The dynamics of residential segregation in buffalo: An agent-based simulation. Urban Studies, 46(13), 2749-2770. https://doi.org/10.1177/0042098009346326

Publisher's Note Springer Nature remains neutral with regard to jurisdictional claims in published maps and institutional affiliations. 